\title{
The Role of Pregnancy Outcomes in the Maternal Mortality Rates of Two Areas in Matlab, Bangladesh
}

\author{
ByMizanur \\ Rahman, Julie \\ DaVanzo and \\ Abdur Razzaque
}

Mizanur Rahman is senior research advisor, Pathfinder International, Watertown,

MA, USA. Julie

DaVanzo is senior

economist, RAND

Corporation, Santa

Monica, CA, USA.

Abdur Razzaque is scientist, International Centre for Diarrhoeal

Disease Research, Bangladesh, Dhaka.

CONTEXT: The Matlab Maternal Child Health-Family Planning (MCH-FP) project provides maternity care as part of its reproductive health services. It is important to assess whether this project has reduced maternal mortality and, if so, whether this was due to differences between the MCH-FP area (which received project services) and the comparison area (which did not) in pregnancy rates, pregnancy outcomes or case-fatality rates.

METHODS: Data from the Matlab Demographic Surveillance System on 165,894 pregnancies over the period 1982-2005 were used to calculate four measures of maternal mortality for the MCH-FP and comparison areas. Mortality risk was examined by type of pregnancy outcome and by area, and bivariate and logistic regression analyses were used to generate unadjusted and adjusted odds ratios, respectively.

RESULTS: The maternal mortality rate of 35 deaths per 100,000 women of reproductive age in the MCH-FP area was $37 \%$ lower than that in the comparison area (56 deaths per 100,000). In both areas, the maternal mortality risk was considerably higher for pregnancies that ended in induced abortion, miscarriage or stillbirth than for those that resulted in live birth (odds ratios, 4.2, 2.0 and 17.4, respectively). The difference in maternal mortality rates between the two areas was mainly a result of the MCH-FP area's lower pregnancy rate and its lower case-fatality rates for induced abortions, miscarriages and stillbirths.

CONCLUSIONS: Interventions to increase contraceptive use; to reduce the incidence of induced abortion, miscarriage and stillbirth; to improve the management of such outcomes; and to strengthen antenatal care could substantially reduce maternal mortality in Bangladesh and similar countries.

International Perspectives on Sexual and Reproductive Health, 2010, 36(4):170-177

Each year,more than 350,000 women die from pregnancyor delivery-related causes and the vast majority of these deaths occur in developing countries. ${ }^{1}$ Each pregnancy puts a woman at risk of maternal death, but women who have induced abortions, miscarriages or stillbirths have been found to be at a higher risk of maternal mortality than those who have live births. ${ }^{2-4}$ Most induced abortions in developing countries are performed in unsafe conditions ${ }^{5}$ and carry a high risk of mortality. ${ }^{6}$ Miscarriages have been found to carry a lower risk of maternal mortality than induced abortions, while stillbirths have been associated with a higher risk of maternal death than have live births. $^{4}$

Bangladesh, a country with unfavorable socioeconomic conditions, has been a family planning success story, achieving a relatively low level of fertility-2.7 births per woman-according to data from 2004 to $2007 .^{7}$ For the period 1998-2001, the nation had a moderate level of maternal mortality-322 deaths per 100,000 live births-especially considering its poorly managed and inefficient health infrastructure and low rate of institutionalized deliveries; ${ }^{8}$ nationwide, about $15 \%$ of deliveries take place in facilities. ${ }^{9}$ Regional data suggest that about 4\%, 6\% and $3 \%$ of pregnancies end in induced abortion, miscarriage and stillbirth, respectively. ${ }^{9}$

\section{BACKGROUND}

Matlab, a rural subdistrict of Bangladesh, is well known for its Demographic Surveillance System (DSS) and its Maternal Child Health-Family Planning (MCH-FP) project, which provides intensive family planning and maternal and child health services in half of the area covered by the DSS. ${ }^{10-12}$ The other half, known as the comparison area, receives the normal government services, which are similar to those in the MCH-FP area but of lower quality and intensity. Moreover, these services do not include safe motherhood care, which may significantly improve maternal health.

\section{Maternity Care in Matlab}

Most deliveries in Matlab take place at home in the presence of traditional birth attendants, though institutional deliveries have been increasing in the MCH-FP area in recent years. ${ }^{9,13}$ Both areas of Matlab have access to the Chandpur government district hospital and to private clinics that provide emergency and intensive services, including caesarean section and blood transfusion. However, about half of the villages in both areas are relatively remote and have less access to transportation to Chandpur; Matlab residents also seek higher-level health services in Narayanganj, a commercial town 4-5 hours away by road 
or river transportation.

Since 1977, women in the MCH-FP area have received a series of carefully designed reproductive health interventions that may directly or indirectly affect maternal health and mortality. Between 1978 and 2001, female community health workers provided family planning counseling and supplies of injectables, pills and condoms at women's homes during biweekly or monthly visits. Four health centers were established in 1987 in the MCH-FP area, and since 2001, these centers have provided health and family planning services. Tetanus immunization was introduced in 1979, and coverage has been universal since 1990. Antenatal screening-a basic safe motherhood interventionbegan in 1982 in the MCH-FP area, and is conducted by female health workers using a simple screening tool.

Between 1987 and 2001, additional safe motherhood interventions were introduced in the MCH-FP area. In 1987, four trained midwives were posted in each of two of the four new health centers; their tasks were to be on 24hour call to attend home deliveries and provide basic obstetric care. Midwives also encouraged family members of pregnant women who experienced complications to take them to the Matlab Heath Center, where emergency care (but not caesarean section or blood transfusion) is available; women with serious complications were transported to the district hospital in Chandpur. In 1990, additional midwives were posted in the other two health centers to provide delivery and obstetric care. Furthermore, pregnant women in the MCH-FP area were advised to contact a midwife for counseling, antenatal and delivery services; they received an illustrated card with information about antenatal care and about signs of danger related to pregnancy. Female community health workers were also trained to refer women with danger signs or pregnancy complications to midwives or paramedics. Between 1996 and 2001, maternity care was gradually redesigned to be facility-based, and as basic obstetric care began to be provided in the four health centers, home-based delivery care by midwives was withdrawn. Overall, the project has made systematic efforts to increase institutional deliveries in the four health centers. ${ }^{11,13-16}$

During 1996-2002, 58\% of pregnant women in the $\mathrm{MCH}-\mathrm{FP}$ area received at least one antenatal checkup, and $52 \%$ received a checkup in the third trimester. ${ }^{17}$ Recently, institutional deliveries have increased remarkably in the MCH-FP area. ${ }^{13}$ In the early 1990s, only a few births occurred in health facilities; by 2005, the percentage of such births had increased to more than $30 \%$, which had further increased to $66 \%$ by $2008 .{ }^{9}$ In contrast, only $18 \%$ of deliveries in the comparison area took place in health facilities in 2008. ${ }^{9}$

\section{Induced Abortion in Bangladesh}

Induced abortion is legal in Bangladesh when it is performed to save a woman's life. In addition, early uterine evacuation-or menstrual regulation-using manual or electric vacuum aspiration is permitted within 10 weeks of a woman's last menstrual period. The procedure is available from trained female paramedics at the government and private health centers in both Matlab areas. The $\mathrm{MCH}$ FP project does not provide pregnancy termination services, but the induced abortions that do occur in the $\mathrm{MCH}$ FP area are more likely to be menstrual regulations than those performed in the comparison area. ${ }^{18}$ This procedure carries a considerably lower risk of maternal mortality than abortions performed by traditional healers; such healers, as well as abortions performed by them, are still common in each area. ${ }^{19}$ The husband's consent is not legally required prior to menstrual regulation, but many providers ask for it.

\section{Maternal and Child Health Outcomes}

The MCH-FP area has lower rates of fertility, ${ }^{9}$ induced abortion, ${ }^{20}$ miscarriage ${ }^{21}$ and stillbirth ${ }^{22}$ than the comparison area, and greater antenatal care coverage and better access to basic and emergency obstetric care. ${ }^{9,14}$

In both areas, contraceptive prevalence has increased over time: In the MCH-FP area, it rose from 46\% in 1984 to $70 \%$ in 1999 , while in the comparison area it grew from $16 \%$ in 1984 to $51 \%$ by $1999 .{ }^{21}$ Meanwhile, the total fertility rate in the MCH-FP area declined from about five births per woman in the early 1980s to three births in the 2000s, whereas the rate in the comparison area was one birth higher than the MCH-FP rate in each period. ${ }^{21}$ Since 2006, however, fertility rates have converged in the two areas, at around 2.5 children per woman. Furthermore, infant mortality rates declined in the MCH-FP area, from about 100 deaths per 1,000 live births in the early 1980s to 21 deaths per 1,000 in 2008, and from about 120 deaths per 1,000 live births to 36 deaths per 1,000 over the same period in the comparison area. ${ }^{9,21}$ According to earlier studies, the comparison area is typical of much of Bangladesh in contraceptive use, ${ }^{21}$ fertility and childhood mortality, ${ }^{7}$ and maternal mortality. ${ }^{8}$

In this article, we compare maternal mortality in the MCH-FP area with that in the comparison area. We investigate the extent to which the MCH-FP area's lower pregnancy rates; lower incidence of induced abortion, miscarriage and stillbirth; and better management of pregnancies and deliveries-especially those that did not result in a live birth-help explain the difference in maternal mortality between these areas during the period studied. An understanding of the factors associated with mortality differences could help in the design of programmatic interventions to reduce maternal mortality in Bangladesh and elsewhere.

\section{METHODS \\ Data}

The Matlab DSS collects longitudinal data on pregnancy outcomes and maternal deaths in both the MCH-FP and comparison areas. Female community health workers have made regular visits to each household (biweekly between 1966 and 1999, monthly between 2000 and 2006, 
and bimonthly since 2007), and record pregnancy status at the time of the visit, as well as any pregnancy outcome that occurred since the prior visit.* The data on induced abortions and miscarriages are considered reliable, because through their frequent household visits the female health workers have established themselves as trustworthy and so are in a good position to collect accurate information on pregnancy outcomes. ${ }^{10}$ Even if some underreporting of miscarriages or induced abortions occurs, the extent of the underreporting should not differ significantly between the MCH-FP and comparison areas. ${ }^{23}$

The DSS records on deaths are reliable, especially for adults, but maternal deaths may be underreported because some may be misclassified as due to other causes. According to the 10th revision of the International Classification of Diseases (ICD-10), a maternal death is "the death of a woman during pregnancy or within 42 days of pregnancy outcome from any cause related to or aggravated by the pregnancy or its management, but not from accidental or incidental causes." ${ }^{24}$ Investigators have collected further information on maternal mortality in Matlab to improve the identification of maternal deaths that occurred between 1976 and 2005, ,4,16,25-27 and have updated the DSS death files accordingly. They expanded the ICD-10 definition to include deaths within 90 days of a pregnancy outcome, ${ }^{28}$ which is the definition used in this study.

We analyzed maternal mortality for a sample of 165,894 singleton pregnancy outcomes that occurred in Matlab during 1982-2005 by matching death records through the unique DSS identification numbers. We excluded 1,711 pregnancies ( $1 \%$ of the sample) that involved twins or triplets, because such outcomes carry an additional risk of maternal death. Our analysis considered the period 1982-2005 for two main reasons. First, basic safe motherhood activities in the form of antenatal care screening began in 1982 in the MCH-FP area; before that year, only family planning and child health interventions were in place. Second, although maternal mortality data are cur-

\begin{tabular}{|c|c|c|c|c|}
\hline Measure & Overall & $\mathrm{MCH}-\mathrm{FP}$ & Comparison & $\begin{array}{l}\text { MCH-FP/ } \\
\text { comparison }\end{array}$ \\
\hline $\begin{array}{l}\text { Maternal mortality ratio } \\
\text { (per 100,000 live births) }\end{array}$ & 381 & 328 & 428 & $0.77^{* * *}$ \\
\hline $\begin{array}{l}\text { Maternal mortality risk } \\
\text { (per } 100,000 \text { pregnancies) }\end{array}$ & 333 & 292 & 369 & $0.79 * * *$ \\
\hline $\begin{array}{l}\text { Maternal mortality rate } \\
\text { (per 100,000 women aged 15-49) }\end{array}$ & 44.8 & 34.8 & 55.6 & $0.63^{* * *}$ \\
\hline $\begin{array}{l}\text { Lifetime risk of maternal mortality } \\
\text { (per 100,000 women aged 15-49) }\end{array}$ & 1,567 & 1,217 & 1,945 & $0.63^{* * *}$ \\
\hline Pregnancies per woman per year & 0.13 & 0.12 & 0.15 & $0.79 * * *$ \\
\hline Live births per pregnancy & 0.87 & 0.89 & 0.86 & $1.03^{* *}$ \\
\hline $\begin{array}{l}\text { Lifetime chance of dying from } \\
\text { maternal causes }\end{array}$ & 1 in 63 & 1 in 82 & 1 in 51 & na \\
\hline No.of maternal deaths & 553 & 223 & 330 & na \\
\hline No. of live births & 145,018 & 67,985 & 77,033 & na \\
\hline No.of pregnancies & 165,894 & 76,448 & 89,446 & na \\
\hline No.of woman-years & $1,234,901$ & 641,151 & 593,750 & na \\
\hline
\end{tabular}

rently available through 2008, the classification of deaths after 2005 was not as rigorous as that used before then.

We considered 553 maternal deaths: Of these, 201 women died during pregnancy (it was unknown whether any of them were carrying multiple fetuses), 305 died within 42 days of the end of the pregnancy and 47 died 43-90 days after the pregnancy outcome. Although these 47 deaths would not be classified as maternal deaths according to ICD-10, we retained them for this analysis, since they were recorded as maternal deaths in the DSS. As a check, we repeated the analysis without classifying these cases as maternal deaths, and the main findings remained unaltered.

\section{Measures}

We examined four measures of maternal mortality. We first looked at the maternal mortality ratio, which is defined as the number of maternal deaths per 100,000 live births. This measure is widely used and allowed us to compare our results for Matlab with those from other studies. However, because the denominator is the number of births rather than the number of pregnancies, the maternal mortality ratio does not represent the mortality risk associated with each pregnancy. (The mortality ratio is widely used because most data sets lack information on pregnancy outcomes other than live births.)

Next, we considered maternal mortality risk, which is defined as maternal deaths per 100,000 pregnancies. It measures the likelihood that a pregnancy will result in a maternal death. Other studies of maternal mortality, including some in Matlab, have also used this measure. ${ }^{14,29}$ The risk of maternal mortality will always be lower than the maternal mortality ratio because the denominator of the former is larger than that of the latter. We examined maternal mortality risks for all pregnancies and also for those with particular outcomes.

Our final two measures are the maternal mortality rate, which is the probability that a woman will die from a maternal cause in a year, and women's lifetime risk of maternal mortality. The maternal mortality rate is defined as the number of maternal deaths per 100,000 women of reproductive age (aged 15-49), and it reflects not only the risk of maternal death per pregnancy, but also the pregnancy rate in the population. Because we present averages of data for the period 1982-2005, the denominator for our rate is woman-years. The lifetime risk is calculated by multiplying the maternal mortality rate by 35 (the number of years between ages 15 and 49).

\section{Analysis}

Most of our analyses focused on the risk of maternal mortality, and we assessed how this risk varied by pregnancy outcome (induced abortion, spontaneous abortion or mis-

*The DSS uses the following definitions: A live birth is the delivery of a live baby at any gestational age; a stillbirth is a fetal loss at 28 weeks' gestation or later; a spontaneous abortion, or miscarriage, is a fetal loss prior to 28 weeks' gestation; and induced abortion is the intentional termination of a pregnancy. 
carriage, stillbirth, live birth or death while pregnant before experiencing an outcome) and area (MCH-FP or comparison). The maternal mortality risk for each type of pregnancy outcome represents the case-fatality rate for women with that outcome.

We calculated unadjusted odds ratios to compare the mortality risks between areas or pregnancy outcomes, as well as between both areas and outcomes. We then calculated adjusted odds ratios of the mortality risks associated with different types of pregnancy outcomes in the two areas, using a logistic regression model that controlled for the following demographic and socioeconomic variables, which have been shown or hypothesized to affect women's likelihood of dying from pregnancy-related causes: ${ }^{14}$ maternal age, pregnancy order, prior child death, prior pregnancy loss, maternal education, household space (a proxy for household wealth), religion and calendar year of the pregnancy outcome. This analysis included interactions of outcome and area to allow the outcome effects to differ between areas.

Finally, we performed a simulation exercise to assess the extent to which the difference in maternal mortality rates between the areas was attributable to their differences in pregnancy rates, distribution of pregnancy outcomes and casefatality rates associated with outcomes. For the assessment of the effects of the last two factors, the case-fatality rates of each area were applied to the pregnancy-outcome distribution of the other area, and these simulated risks of maternal mortality were compared to the observed risks of maternal mortality in each area.

\section{RESULTS}

\section{Maternal Mortality Measures}

For the period 1982-2005, the maternal mortality ratio in Matlab was 381 deaths per 100,000 live births (Table 1). The maternal mortality risk was lower-333 deaths per 100,000 pregnancies. The average annual maternal mortality rate was 44.8 pregnancy-related deaths per 100,000 women of reproductive age. Finally, the lifetime risk of maternal mortality over this period was 1,567 deaths per 100,000 women; that is, a woman had a 1 in 63 chance of dying from a maternal cause during her reproductive lifetime.

For all indicators of maternal mortality, the value for the MCH-FP area was significantly lower than that for the comparison area: The maternal mortality ratio was 23\% lower, and the maternal mortality risk was $21 \%$ lower. (The difference is due to the fact that more pregnancies in the former area resulted in live births.) Both the maternal mortality rate and the lifetime risk of dying from maternal causes were $37 \%$ lower in the MCH-FP area (e.g., the maternal mortality rates in the MCH-FP and comparison areas were 34.8 deaths and 55.6 deaths per 100,000 women, respectively). Women in the comparison area had a one in 51 chance of dying from maternal causes, while those in the MCH-FP area had a one in 82 chance. This difference between the areas for the latter two measures was greater than
TABLE 2. Distribution of maternal deaths, by outcome or woman's death during pregnancy, and of pregnancies with an outcome, by outcome

\begin{tabular}{|lcccc} 
Outcome & $\begin{array}{l}\text { No. of } \\
\text { deaths }\end{array}$ & $\begin{array}{l}\text { \% of all } \\
\text { deaths } \\
(\mathrm{N}=553)\end{array}$ & $\begin{array}{l}\text { \% of deaths } \\
\text { associated } \\
\text { with outcome } \\
(\mathrm{N}=352)\end{array}$ & $\begin{array}{l}\text { \% of pregnancies } \\
\text { with an outcome } \\
(\mathrm{N}=165,693)\end{array}$ \\
\hline $\begin{array}{l}\text { Woman died during pregnancyt } \\
\text { Induced abortion }\end{array}$ & 201 & 36.3 & na & na \\
$\begin{array}{l}\text { Miscarriage } \\
\text { Stillbirth }\end{array}$ & 25 & 5.8 & 9.1 & 3.6 \\
Live birth & 108 & 19.5 & 7.1 & 5.9 \\
All & 187 & 33.8 & 53.1 & 8.0 \\
\hline These women died before having a pregnancy outcome. Note: na=not applicable. &
\end{tabular}

that for the first two measures because women in the $\mathrm{MCH}$ FP area had a lower average annual rate of pregnancy than those in the comparison area (12\% vs. 15\%).

\section{Mortality Risk by Pregnancy Outcome and Area}

Among women who died of pregnancy-related causes, $36 \%$ died during pregnancy, $6 \%$ of deaths were among women who had an induced abortion, $5 \%$ were among women who had a miscarriage, 20\% occurred after a stillbirth and 34\% resulted from complications of a live birth (Table 2). When only women who had a pregnancy outcome were considered, $9 \%$ of deaths followed an abortion, $7 \%$ a miscarriage, $31 \%$ a stillbirth and $53 \%$ a live birth. Thus, the $13 \%$ of pregnancies that ended in an abortion, a miscarriage or a stillbirth (4\%, 6\% and 3\%, respectively) accounted for $47 \%$ of maternal deaths, while the $88 \%$ of pregnancies that ended in live births accounted for 53\% of maternal deaths. Notably, stillbirths-representing only $3 \%$ of all outcomes-accounted for 31\% of maternal deaths associated with a pregnancy outcome.

Pregnancies in the MCH-FP area were more likely than those in the comparison area to result in live births (89\% vs. $86 \%$; odds ratio, 1.3-Table 3). The odds of a pregnancy ending in an induced abortion, a miscarriage or a stillbirth were lower in the MCH-FP area than in the comparison area (0.5, 0.9 and 0.9 , respectively); there was no difference between areas in the likelihood of a woman dying during pregnancy.

\begin{tabular}{|c|c|c|c|}
\hline Outcome & $\mathrm{MCH}-\mathrm{FP}$ & Comparison & $\begin{array}{l}\text { Odds ratio } \\
\text { (MCH-FP vs. } \\
\text { comparison) }\end{array}$ \\
\hline Live birth & 88.9 & 86.1 & $1.29 * * *$ \\
\hline All other outcomes & 11.0 & 13.8 & $0.77^{* *}$ \\
\hline Induced abortion & 2.4 & 4.6 & $0.52^{* * *}$ \\
\hline Miscarriage & 5.7 & 6.1 & $0.93^{* *}$ \\
\hline Stillbirth & 2.8 & 3.1 & $0.92^{* *}$ \\
\hline $\begin{array}{l}\text { Woman died during } \\
\text { pregnancy } \dagger\end{array}$ & 0.1 & 0.1 & 0.89 \\
\hline Total & 100.0 & 100.0 & na \\
\hline
\end{tabular}

${ }^{* *} \mathrm{p}<.01 .{ }^{* * *} \mathrm{p}<.001+$ These women died before having a pregnancy outcome. Notes: $\mathrm{MCH}-\mathrm{FP}=$ Maternal Child Health-Family Planning. na=not applicable. 


\begin{tabular}{|c|c|c|c|c|c|}
\hline \multirow[t]{2}{*}{ Outcome } & \multicolumn{2}{|c|}{ Both areas } & \multirow[t]{2}{*}{$\mathrm{MCH}-\mathrm{FP}$} & \multirow[t]{2}{*}{ Comparison } & \multirow{2}{*}{$\begin{array}{l}\text { Odds ratio } \\
\text { (MCH-FP vs. } \\
\text { comparison) }\end{array}$} \\
\hline & $\begin{array}{l}\text { Maternal } \\
\text { mortality } \\
\text { risk }\end{array}$ & $\begin{array}{l}\text { Odds ratio } \\
\text { (vs.live } \\
\text { births) }\end{array}$ & & & \\
\hline Live birth (ref) & 129 & 1.00 & 129 & 129 & 1.00 \\
\hline All other outcomes & 798 & $6.23^{* * *}$ & 573 & 951 & $0.60^{* * *}$ \\
\hline Induced abortion & 541 & $4.22^{* *}$ & 327 & 638 & 0.51 \\
\hline Miscarriage & 254 & $1.97^{* *}$ & 160 & 330 & 0.48 \\
\hline Stillbirth & 2,196 & $17.38^{* * *}$ & 1,621 & 2,645 & $0.61^{*}$ \\
\hline $\begin{array}{l}\text { Woman died during } \\
\text { pregnancyt }\end{array}$ & 121 & 0.94 & 114 & 127 & 0.89 \\
\hline All pregnancies & 333 & na & 292 & 369 & $0.79^{* *}$ \\
\hline
\end{tabular}

${ }^{*} \mathrm{p}<.05 .{ }^{* *} \mathrm{p}<.01 .{ }^{* * *} \mathrm{p}<.001$. + These women died before having a pregnancy outcome; all pregnant women were considered at risk of this outcome. Notes: $\mathrm{MCH}-\mathrm{FP}=$ Maternal Child Health-Family Planning.na=not applicable. ref=reference category. and the risk of dying during pregnancy was $11 \%$ lower. However, because of the relatively small sample sizes for these four categories, only the difference for stillbirths was statistically significant.

In a logistic regression model that controlled for demographic and socioeconomic variables (not shown), the adjusted odds were similar to the unadjusted odds presented for the two areas combined in Table 4. Compared with the risk of dying during a live birth, risks were elevated in the MCH-FP and the comparison area for induced abortion ( 2.5 vs. 5.1 ), miscarriage ( 1.3 vs. 2.5 ) and stillbirth (11.5 vs. 19.6-p<.05); the difference in odds ratios between the areas was significant only for stillbirths $(\mathrm{p}<.05)$.

\section{Role of Pregnancy Rates and Outcomes}

The difference in maternal mortality rates between the two areas was due to differences in both pregnancy rates and the average risk of maternal mortality (the maternal mortality rate is the product of these two measures). As Table 1 showed, both the pregnancy rate and the maternal mortality risk in the MCH-FP area were $21 \%$ lower than those measures in the comparison area, hence they contributed equally to the lower rate of maternal mortality in the former area.

Finally, the simulation exercise generated hypothetical maternal mortality risks for each area by substituting either the distribution of pregnancy outcomes or the casefatality rates of the other area. One simulated risk was calculated by applying the case-fatality rates of the MCH-FP area to the pregnancy outcome distribution of the comparison area, and the other was calculated by applying the case-fatality rates of the comparison area to the outcome distribution of the MCH-FP area (Table 5).

The simulations showed that most of the difference in overall maternal mortality risk was due to differences in case-fatality rates. If the case-fatality rates of the comparison area remained the same but the pregnancy outcome distribution were changed to that of the MCH-FP area, the mortality risk would decrease by $5 \%$, from 369 to 351 deaths per 100,000 pregnancies. In contrast, if the distribution of pregnancy outcomes in the comparison area remained the same but the case-fatality rates were changed to those of the MCH-FP area, the mortality risk would decline by $18 \%$, from 369 to 301 deaths per 100,000 pregnancies.

If the MCH-FP area retained its case-fatality rates but had the outcome distribution of the comparison area, its maternal mortality risk would increase by 3\% (from 292 to 301 deaths per 100,000). However, if the MCH-FP area kept its outcome distribution but had the case-fatality rates of the comparison area, its mortality risk would increase by $20 \%$, from 292 to 351 deaths per 100,000. Thus, of the observed difference of 77 maternal deaths per 100,000 pregnancies between the two areas, $12-23 \%$ may be attributable to differences in the distribution of pregnancy outcomes, while $77-88 \%$ may be attributable to differences in case-fatality rates. 


\section{DISCUSSION}

In this analysis of a large sample of pregnancy outcomes and maternal deaths over a 24-year period, we found that the maternal mortality risk in Matlab as a whole was more than six times as high for pregnancies that did not result in a live birth as for those that resulted in a singleton live birth. If all pregnancies in Matlab resulted in singleton live births, or if women with other pregnancy outcomes had a mortality risk the same as that associated with singleton live births and no women died during pregnancy, the maternal mortality risk would be $61 \%$ lower than the observed overall risk of 333 deaths. If a comparable decrease from the level of maternal mortality in 1990 could be achieved by 2015 , it would come close to meeting the Millennium Development Goal for reduction of maternal deaths.

Many of our results are similar to those found in other studies conducted in Matlab. The level of mortality risk per 100,000 pregnancies and the lifetime maternal mortality risk reported here are comparable to those reported elsewhere. ${ }^{29}$ Our finding of a very high risk of mortality associated with stillbirth is similar to that found in another study from Matlab. ${ }^{4}$ In addition, our research has confirmed previous findings that maternal mortality was significantly lower in the MCH-FP area than in the comparison area. ${ }^{14}$

We found that the maternal mortality rate and the lifetime risk of maternal mortality were each 37\% lower in the MCH-FP area. We found three reasons for this difference. First, women in the MCH-FP area had fewer pregnancies and hence were less often exposed to pregnancy-related risks. Second, the pregnancies that women in the MCH-FP area did have were less likely to result in induced abortions, miscarriages or stillbirths, all of which had higher risks of maternal mortality than did live births. Third, when women in the MCH-FP area did have abortions, miscarriages and stillbirths, they were less likely to die than women in the comparison area. These differences in casefatality rates accounted for the majority of the difference in overall maternal mortality risks between the two areas.

Each of these differences between the areas was likely due to the interventions that have been in place in the $\mathrm{MCH}-\mathrm{FP}$ area. For example, the lower pregnancy rate in the MCH-FP area can be attributed to its higher contraceptive use rate. These interventions may also explain the lower proportions of pregnancies that resulted in induced abortions, miscarriages and stillbirths. The greater use of contraceptives in the MCH-FP area also led to fewer unintended pregnancies, and hence fewer induced abortions. ${ }^{20}$ Women in the MCH-FP area had better access to reproductive health services and information, and so pregnant women were more likely to get health care from community- and facility-based providers, which presumably resulted in fewer miscarriages and stillbirths.

The lower rate of mortality among women whose pregnancies ended in induced abortion, miscarriage or stillbirth in the MCH-FP area, compared with that among their coun- terparts in the comparison area, suggests that the former area's maternity care program has been able to more effectively manage pregnancies that do not result in live births, especially stillbirths. As mentioned earlier, women in the MCH-FP area were more likely to use antenatal care and maternity services both at home and in hospitals, especially since early 2000. A substantial proportion of their deliveries took place in MCH-FP project facilities, which can treat complications and also have an effective referral system to higher-level facilities. Because they had better access to antenatal and maternity services than women in the comparison area, women in the MCH-FP area who had miscarriages or stillbirths probably sought health care more often and more quickly, and this likely reduced the risk of dying from such outcomes. Nonetheless, it is puzzling that the $\mathrm{MCH}$ FP project does not seem to have resulted in fewer deaths during pregnancy (before any outcome) or to have reduced mortality among women who have live births. Further research should investigate these issues.

Several factors help explain the lower maternal mortality risk associated with induced abortions in the MCH-FP area. The maternity centers equipped with postabortion care services in this area are likely to reduce the risk of women dying from unsafe abortions, which are still quite common in Bangladesh. MCH-FP maternity center staff and community-based midwives direct women who require blood transfusion or dilation and curettage to the nearby district hospital in Chandpur. ${ }^{30}$ These services are not available in the comparison area. Furthermore, women in the MCH-FP area are more likely than those in the comparison area to use menstrual regulation rather than seek induced abortions from untrained providers. ${ }^{18}$

The very high risk of maternal mortality associated with stillbirths, especially in the comparison area, deserves public health attention. Stillbirths that occur at full term or near full term are likely to be associated with delivery complications that do not receive appropriate and timely interventions. Most women in Bangladesh give birth at home with the assistance of untrained birth attendants. When complications occur, the woman's relatives may adopt a wait-and-see approach or seek help from untrained or traditional health care providers. The extent to which women receive postnatal care after pregnancy outcomes other than live births merits further study.

The Matlab MCH-FP project has demonstrated that better family planning services-in terms of access and quality-can reduce pregnancy rates and, by also reducing unintended pregnancies, help lower the incidence of induced abortion. ${ }^{14,20}$ However, very little is known about how to prevent miscarriages and stillbirths. Our research in Matlab has shown that short interpregnancy intervals are associated with a high incidence of miscarriage and stillbirth. ${ }^{31}$ Therefore, interventions that promote the healthy timing and spacing of pregnancies should be useful in reducing these outcomes. We have also found that women with an interpregnancy interval of more than five years are more likely than others to have a miscarriage or stillbirth. 
Hence, counseling and monitoring of women who have a subsequent pregnancy after a long period of time may help reduce the incidence of these two outcomes. Furthermore, studies have found a pattern of repeated miscarriages and stillbirths among women, ${ }^{31,32}$ and therefore monitoring women with a history of such outcomes may help them avoid a repetition. There is some evidence that the incidence of stillbirth is declining in both areas of Matlab, with a greater decline in the MCH-FP area. ${ }^{22}$ Further research should focus on the factors associated with pregnancy losses. The fact that about a third of maternal deaths occur during pregnancy prior to an outcome underscores the importance of antenatal care and the need to identify lifethreatening conditions.

\section{Conclusions}

Maternity care providers and community health workers should counsel pregnant women about the mortality risks of miscarriages, stillbirths and unsafe abortions, and should advise them to immediately contact trained providers if they have such outcomes. Women who experience these outcomes should be monitored for a longer time than those who have live births, because improved management of these outcomes can reduce maternal mortality.

If linked with high-level obstetric care, greater access to maternity care services could reduce the incidence of miscarriage and stillbirth, thus decreasing the number of women dying from the complications of such outcomes. More effective policies and safer management of induced abortion, miscarriage and stillbirth could have a strong and positive impact in reducing maternal mortality in Bangladesh and similar countries.

\section{REFERENCES}

1. World Health Organization (WHO), United Nations Children's Fund (UNICEF), United Nations Population Fund (UNFPA) and World Bank, Trends in Maternal Mortality: 1990 to 2008, Geneva: WHO, 2010.

2. Gissler M et al., Pregnancy-associated mortality after birth, spontaneous abortion or induced abortion in Finland, 1987-2000, American Journal of Obstetrics \& Gynecology, 2004, 190(2):422-427.

3. Reardon DC et al., Deaths associated with pregnancy outcome: a record linkage study of low income women, Southern Medical Journal, 2002, 95(8):834-841.

4. Hurt LS et al., Duration and magnitude of mortality after pregnancy in rural Bangladesh, International Journal of Epidemiology, 2008, 37(2):397-404

5. Singh S, Hospital admissions resulting from unsafe abortion: estimates from 13 developing countries, Lancet, 2006, 368(9550):18871892.

6. Khan KS et al., WHO analysis of causes of maternal death: a systematic review, Lancet, 2006, 367(9516):1066-1074.

7. National Institute of Population Research and Training (NIPORT), Mitra and Associates, and ORC Macro, Bangladesh Demographic and Health Survey, 2004, Dhaka, Bangladesh: NIPORT and Mitra and Associates; and Calverton, MD, USA: ORC Macro, 2005.

8. NIPORT et al., Bangladesh Maternal Health Services and Maternal Mortality Survey, 2001, Dhaka, Bangladesh: NIPORT and International Centre for Diarrhoeal Disease Research, Bangladesh (ICDDR,B); and Calverton, MD, USA: ORC Macro, 2003.

9. ICDDR,B, Health and Demographic Surveillance System-Matlab: Vol- ume Forty Two, Registration of Health and Demographic Events 2008 , Dhaka, Bangladesh: ICDDR,B, 2010

10. D'Souza S, A population laboratory for studying disease processes and mortality-the Demographic Surveillance System, Matlab, Bangladesh, Special Publication, Dhaka, Bangladesh: ICDDR,B, 1981, No. 13.

11. Fauveau V, Matlab: Women, Children, and Health, Dhaka, Bangladesh: ICDDR,B, 1992

12. Van Ginneken J et al., Health and demographic surveillance in Matlab: past, present, and future, Special Publication, Dhaka, Bangladesh ICDDR,B, 1998, No. 72

13. Chowdhury ME et al., Equity in use of home-based or facility-based skilled obstetric care in rural Bangladesh: observational study, Lancet, 2006, 367(9507):327-332.

14. Chowdhury ME et al., Determinants of reduction in maternal mortality in Matlab, Bangladesh: a 30-year cohort study, Lancet, 2007, 370(9595):1320-1328

15. Ronsmans $C$ et al., Decline in maternal mortality in Matlab, Bangladesh: a cautionary tale, Lancet, 1997, 350(9094):1810-1814.

16. Fauveau $V$ et al., Effect on mortality of community-based maternitycare programme in rural Bangladesh, Lancet, 1991, 338(8776):11831186

17. Razzaque A et al., Pregnancy spacing and maternal morbidity in Matlab, Bangladesh, International Journal of Gynecology \& Obstetrics, 2005, 89(Suppl. 1):S41-S49.

18. DaVanzo J et al., Do family planning services affect choice of abortion method in Bangladesh?, paper presented at the annual meeting of the Population Association of America, Boston, Apr. 1-3, 2004

19. Fauveau $V$ and Blanchet $T$, Deaths from injuries and induced abortion among rural Bangladeshi women, Social Science \& Medicine, 1989, 29(9):1121-1127.

20. Rahman M, DaVanzo J and Razzaque A, Do better family planning services reduce abortion in Bangladesh? Lancet, 2001, 358(9287): 1051-1056

21. ICDDR,B, Health and Demographic Surveillance System, Matlab: Registration of Health and Demographic Events (1983-2005), Dhaka, Bangladesh: ICDDR,B, 2006

22. Ronsmans $C$ et al., Trends in stillbirths, early and late neonatal mortality in rural Bangladesh: the role of public health interventions, Paediatric and Perinatal Epidemiology, 2008, 22(3):269-279.

23. Ahmed K, Sarkar AH and Rahman M, Determinants of induced abortion in rural Bangladesh, Demography India, 1996, 25(1):105-118.

24. WHO, International Statistical Classification of Diseases and Related Health Problems, 10th revision, Geneva: WHO, 1992

25. Koenig MA et al., Maternal mortality in Matlab, Bangladesh, Studies in Family Planning, 1988, 19(2):69-80.

26. Ronsmans $C$ and Campbell O, Short birth intervals don't kill women: evidence from Matlab, Bangladesh, Studies in Family Planning, 1998, 29(3):282-290

27. Dieltiens G et al., Met Need for Life-Saving Obstetric Surgery in Bangladesh: The Matlab-ICDDR,B Cohort-Study of Maternal Mortality 1990-2001 and the Results for a New Indicator to Assess Met Need for LifeSaving Obstetric Surgery, Dhaka, Bangladesh: ICDDR,B, 2005.

28. American Medical Association (AMA) Committee on Maternal and Child Care, A Guide for Maternal Death Studies, Chicago, IL, USA: AMA, 1964

29. Chowdhury ME et al., Causes of maternal mortality decline in Matlab, Bangladesh, Journal of Health, Population and Nutrition, 2009, 27(2):108-123.

30. Maine D et al., Why did maternal mortality decline in Matlab? Studies in Family Planning, 1996, 27(4):179-187.

31. DaVanzo J et al., Effects of interpregnancy interval and outcome of the preceding pregnancy on pregnancy outcomes in Matlab, Bangladesh, BJOG: An International Journal of Obstetrics and Gynaecology, 2007, 114(9):1079-1087. 
32. Hathout $\mathrm{H}$ et al., Influence of pregnancy outcome on subsequent pregnancy, International Journal of Gynecology $\&$ Obstetrics, 1982, 20(2):145-147.

\section{RESUMEN}

Contexto: El proyecto Maternal Child Health-Family Planning (MCH-FP) en Matlab, Bangladesh (proyecto de Salud Materna e Infantil-Planificación Familiar), proporciona atención materna como parte de sus servicios de salud reproductiva. Es importante evaluar si este proyecto ha reducido la mortalidad materna y, de ser así, determinar si esto se debió a diferencias en tasas de embarazo, resultados del embarazo o tasas de casos fatales entre el área MCH-FP (que recibió servicios del proyecto) y el área de comparación (que no los recibió). Métodos: Datos del Demographic Surveillance System (Sistema de Vigilancia Demográfica) de Matlab referentes a 165,894 embarazos ocurridos en el período 1982-2005 se usaron para calcular cuatro medidas de mortalidad materna para el área MCH-FP y las áreas de comparación. El riesgo de mortalidad se examinó por tipo de resultado del embarazo y por área; y se utilizó análisis de dos variables (no ajustados) y de regresión logística (ajustados) para generar razones de momios.

Resultados: La tasa de mortalidad materna de 35 muertes por 100,000 mujeres en edad reproductiva en el área del proyecto MCH-FP fue 37\% menor que la observada en el área de comparación (56 muertes por 100,000). En ambas áreas, el riesgo de mortalidad materna fue considerablemente más alto para embarazos que terminaron en aborto inducido, aborto espontáneo o muerte fetal que para los que resultaron en nacimientos vivos (razones de momios, 4.2, 2.0 y 17.4, respectivamente). La diferencia en las tasas de mortalidad materna entre las dos áreas fue principalmente resultado de una menor tasa de embarazos en el área MCH-FP y sus menores tasas de casos fatales por abortos inducidos, abortos espontáneos y muertes fetales.

Conclusiones: Las intervenciones para aumentar el uso de anticonceptivos; reducir la incidencia del aborto inducido, aborto espontáneo y muerte fetal; mejorar el manejo de tales resultados; $y$ fortalecer la atención prenatal, podrían reducir sustancialmente la mortalidad materna en Bangladesh y países similares.

\section{RÉSUMÉ}

Contexte: Le projet MCH-FP (Maternal Child HealthFamily Planning) de Matlab apporte des soins de maternité dans le cadre de ses services de santé génésique. Il importe d'évaluer si le projet a fait baisser la mortalité maternelle et, si oui, si la réduction enregistrée tient à des différences de taux de grossesse, d'issue des grossesses ou de taux de létalité entre la zone MCH-FP (bénéficiaire des prestations du projet) et la zone de comparaison (non bénéficiaire de ces prestations).

Méthodes: Les données du Système de surveillance démographique de Matlab relatives à 165.894 grossesses durant la période de 1982 à 2005 ont servi de base au calcul de quatre mesures de mortalité maternelle pour la zone MCH-FP et la zone de comparaison. Le risque de mortalité a été examiné en fonction du type d'issue de la grossesse et de la zone, tandis que les rapports de cotes bruts et corrigés étaient déterminés, respectivement, par analyses de régression bivariée et logistique.

Résultats: Le taux de mortalité maternelle de 35 décès pour 100 mille femmes en âge de procréer dans la zone d'intervention MCH-FP s'est avéré de 37\% inférieur à celui relevé dans la zone de comparaison (56 pour 100 mille). Dans les deux zones, le risque de mortalité maternelle s'est révélé considérablement supérieur pour les grossesses interrompues par IVG, avortement spontané ou mort foctale tardive, par rapport à celles ayant abouti sur une naissance vivante (rapports de probabilités, 4,2, 2,0 et 17,4, respectivement). La différence entre les taux de mortalité maternelle des deux zones tient principalement au taux de grossesse inférieur observé dans la zone MCH-FP et à ses taux de létalité inférieurs aussi concernant l'IVG, l'avortement spontané et la mort foctale tardive.

Conclusions: Les interventions aptes à accroître la pratique contraceptive, à réduire l'incidence de l'IVG, de l'avortement spontané et des morts foetales tardives, à améliorer la gestion de ces issues et à renforcer la prestation de soins prénatals pourraient donner lieu à une baisse substantielle de la mortalité maternelle au Bangladesh et dans les pays comparables.

\section{Acknowledgments}

Support was provided by the Office of Population and Reproductive Health, Bureau for Global Health, U.S. Agency for International Development (USAID), under cooperative agreement HRNA-00-00-00003-00 awarded to the CATALYST Consortium, a partnership between Pathfinder International and the Academy for Educational Development, the Centre for Development and Population Activities, Meridian Group International, Inc., and PROFAMILIA/Colombia. The authors thank Dan Pellegrom and Maureen Norton for their comments and encouragement, and Shahabuddin Ahmed for help with data analysis. The views expressed are those of the authors and do not reflect the opinions of USAID, Pathfinder International, RAND or the International Centre for Diarrhoeal Disease Research, Bangladesh.

Author contact:MRahman@pathfind.org 